\title{
Simulation study of the high-latitude F-layer modification by powerful HF waves with different frequencies for autumn conditions
}

\author{
G. I. Mingaleva, V. S. Mingalev, and I. V. Mingalev \\ Polar Geophysical Institute of the Kola Science Center, Russian Academy of Sciences, Fersman Str.14, Apatity 184209, \\ Murmansk Region, Russia
}

Received: 27 May 2002 - Revised: 19 February 2003 - Accepted: 21 March 2003

\begin{abstract}
The large-scale high-latitude F-region modification by high power radio waves is investigated using a numerical model of the convecting high-latitude ionosphere developed earlier. Simulations are performed for the point with geographic coordinates of the ionospheric heater near Troms $\varnothing$, Scandinavia for autumn conditions. The calculations are made for distinct cases, in which high power waves have different frequencies, both for nocturnal and for daytime conditions. The results of modeling indicate that the frequency of HF waves ought to influence significantly the large-scale F-region modification by high power radio waves in the high-latitude ionosphere.
\end{abstract}

Key words. Ionosphere (active experiments; modeling and forecasting; plasma temperature and density)

\section{Introduction}

Within the past three decades, experiments with high-power, high-frequency radio waves were successfully used for the investigation of the ionospheric plasma's properties. The majority of high-power radio wave heaters have been built in the mid-latitudes (Platteville, Arecibo, Nizhny Novgorod, etc.). Only a few ionospheric heaters have been built and utilized for the modification of the high-latitude ionosphere, namely the HF heating facility near Monchegorsk, Kola Peninsula, the HF facility near Troms $\varnothing$, Scandinavia, the HIPAS heating facility near Fairbanks, Alaska, and the HAARP facility near Gakona, Alaska. Using these heaters, many interesting results concerning the high-latitude ionosphere modification by a powerful HF wave have been obtained (Kapustin et al., 1977; Stubbe and Kopka, 1983; Wagner et al., 1990; Rietveld et al., 1993 and references therein; Stubbe, 1996 and references therein; Rodriguez et al., 1998). However, the bulk of the papers just mentioned have been applied to the lower high-latitude ionosphere (D- and E-regions). Up

Correspondence to: V. S. Mingalev

(mingalev@pgi.kolasc.net.ru) to now, there have been much less successful experimental studies of the large-scale high-latitude F-region modification by HF radio waves. In particular, results of observations of the modification of F-region electron temperatures and densities during HF heating have been presented by several groups (Jones et al., 1986; Honary et al., 1995; Robinson et al., 1996; Tereshchenko et al., 2000; Gustavsson et al., 2001). In contrast to the limited work on the large-scale high-latitude F-region modification, many experimental studies have been applied to the large-scale mid-latitude F-region modification by powerful $\mathrm{HF}$ waves and many interesting results were obtained (Utlaut and Violette, 1974; Gordon and Carlson, 1974; Mantas et al., 1981; Djuth et al., 1987; Duncan et al., 1988; Hansen et al., 1992; Mantas, 1994; Frolov et al., 1997). It appears that the high-latitude F-region responds more seldom to high power radio waves actions than the mid-latitude Fregion. It may be expected that some specific features, characteristic of the high-latitude F-region ionosphere, decrease the efficiency of the HF heating or obstruct the observation of the F-layer modification.

Many of the details of the response of the high-latitude Fregion to a powerful HF wave may be investigated by using numerical models. The numerical model of the high-latitude F-region, which can be affected by a powerful HF wave, has been developed by Mingaleva and Mingalev (1997); this paper also has presented the results of simulation of the expected F-layer response at auroral latitudes to high-power, high-frequency waves. The results of the numerical simulation, performed for the point with geographic coordinates of the ionospheric heater near Troms $\varnothing$, Scandinavia, have indicated that significant variations in the electron temperature profiles can be produced by powerful HF waves in the highlatitude F-layer. The variations of the electron temperature profiles can ultimately lead to a detectable decrease in the electron concentration at the level of the F-region peak.

It can be noted that the results by Mingaleva and Mingalev (1997) have been obtained for the fixed value of the effective absorbed power (EAP) only. A computational study of how the EAP affects the high-latitude F-layer response to 
high power radio waves has been carried out by Mingalev and Mingaleva (1999). The calculations have been made for distinct cases in which the EAP varies from 5 to $120 \mathrm{MW}$. It turns out that the appreciable variations of the electron temperature, positive ion velocity, and electron concentration profiles can be produced by HF heating in the high-latitude Fregion, with the maximal amplitudes of variations depending significantly on the value of the EAP. The simulation results indicate that the more the EAP is, the higher the values of maximal amplitudes of variations of ionospheric quantities, produced by the HF heating, ought to be.

In the studies by Mingaleva and Mingalev (1997) and Mingalev and Mingaleva (1999) cited above, the results were obtained for nocturnal conditions and for fixed values of the wave frequency. It is of interest to study how the wave frequency influences the expected high-latitude F-region response to a powerful HF wave. The purpose of this paper is to simulate time variations of ionospheric quantities in the high-latitude F-region produced by the HF heating facility near Troms $\varnothing$, Scandinavia for distinct cases, in which HF radio waves have different frequencies, not only for nocturnal but also for daytime conditions.

\section{Numerical model}

In the present study, the numerical model of the high-latitude F-region ionosphere, which can be affected by a powerful HF wave, developed earlier by Mingaleva and Mingalev (1997), is used. This model was applied for simulations of the highlatitude F-layer modification by $\mathrm{HF}$ waves with different powers (Mingalev and Mingaleva, 1999). The model takes into account the convection of the ionospheric plasma, strong magnetization of the plasma at F-layer altitudes, and geomagnetic field declination. In the model calculations the temporal history of the ionospheric plasma is traced in the part of the magnetic field tube moving along the convection trajectory through a neutral atmosphere over an ionospheric heater. A part of the magnetic field tube of the ionospheric plasma is considered at distances between 100-700 km from the Earth along the magnetic field line. As a consequence of the strong magnetization of plasma at F-layer altitudes, its motion may be separated into two flows: the first, plasma flow, parallel to the magnetic field; the second, plasma drift in the direction perpendicular to the magnetic field. The parallel plasma flow in the considered part of the magnetic field tube is described by the system of transport equations, which consists of the continuity equation, the equation of motion for ion gas, and heat conduction equations for ion and electron gases. These equations in the reference frame convecting together with a field tube of plasma, whose axis $h$ is directed upwards along the magnetic field line, may be written as follows:

$$
\begin{aligned}
& \frac{\partial N}{\partial t}+\frac{\partial}{\partial h}\left(N V_{i}\right)=q+q_{e}+q_{p}-l, \\
& m_{i} N\left(\frac{\partial V_{i}}{\partial t}+V_{i} \frac{\partial V_{i}}{\partial h}\right)-\frac{4}{3} \frac{\partial}{\partial h}\left(\mu \frac{\partial V_{i}}{\partial h}\right)+\frac{\partial}{\partial h}
\end{aligned}
$$

$$
\begin{aligned}
& {\left[N \kappa\left(T_{i}+T_{e}\right)\right]+m_{i} N g \sin I=m_{i} N \sum_{n=1}^{3} \frac{1}{\tau i n}\left(U_{n}-V_{i}\right),} \\
& \frac{\partial T_{i}}{\partial t}=\frac{1}{M} \frac{\partial}{\partial h}\left(\lambda_{i} \frac{\partial T_{i}}{\partial h}\right)-V_{i} \frac{\partial T_{i}}{\partial h}+\frac{\gamma-1}{N} \\
& \left(\frac{\partial N}{\partial t}+V_{i} \frac{\partial N}{\partial h}\right) T_{i}+\frac{1}{M}\left(P_{i e}+\sum_{n=1}^{3} P_{i n}\right), \\
& \frac{\partial T_{e}}{\partial t}=\frac{1}{M} \frac{\partial}{\partial h}\left(\lambda_{e} \frac{\partial T_{e}}{\partial h}\right)-V_{e} \frac{\partial T_{e}}{\partial h}+\frac{\gamma-1}{N} \\
& \left(\frac{\partial N}{\partial t}+V_{e} \frac{\partial N}{\partial h}\right) T_{e}+\frac{1}{M} \\
& \left(P_{e i}+\sum_{n=1}^{3} P_{e n}+Q+Q_{e}+Q_{p}+Q_{f}-L_{r}-L_{v}-l_{e}-L_{f}\right),
\end{aligned}
$$

where $N$ is the $\mathrm{O}^{+}$ion number density (which is assumed to be equal to the electron density at the F-layer altitudes); $V_{i}$ is the parallel (to the magnetic field) component of the positive ion velocity; $q$ is the photoionization rate; $q_{e}$ is the production rate due to auroral electron bombardment; $q_{p}$ is the production rate due to auroral proton bombardment; $l$ is the positive ion loss rate (taking into account the chemical reactions $\mathrm{O}^{+}+\mathrm{O}_{2} \rightarrow \mathrm{O}_{2}^{+}+\mathrm{O}, \mathrm{O}^{+}+\mathrm{N}_{2} \rightarrow \mathrm{NO}^{+}+\mathrm{N}$, $\mathrm{O}_{2}^{+}+e \rightarrow \mathrm{O}+\mathrm{O}$, and $\left.\mathrm{NO}^{+}+e \rightarrow \mathrm{N}+\mathrm{O}\right) ; m_{i}$ is the positive ion mass; $k$ is Boltzmann's constant; $T_{i}$ and $T_{e}$ are the ion and electron temperatures, respectively; $g$ is the acceleration due to gravity; $I$ is the magnetic field dip angle; $1 / \tau_{\text {in }}$ is the collision frequency between ion and neutral particles of type $n$; $U_{n}$ is the parallel component of velocity of neutral particles of type $n ; M=\frac{3}{2} \kappa N, \gamma=\frac{5}{3} ; V_{e}$ is the parallel component of electron velocity (which is determined from the equation for parallel current); $\mu$ is the ion viscosity coefficient; $\lambda_{i}$ and $\lambda_{e}$ are the ion and electron thermal conductivity coefficients; $Q, Q_{e}, Q_{p}$ and $Q_{f}$ are the electron heating rates due to photoionization, auroral electron bombardment, auroral proton bombardment, and HF heating, respectively; $L_{r}, L_{v}, L_{e}$ and $L_{f}$ are the electron cooling rates due to rotational excitation of molecules $\mathrm{O}_{2}$ and $\mathrm{N}_{2}$, vibrational excitation of molecules $\mathrm{O}_{2}$ and $\mathrm{N}_{2}$, electronic excitation of atoms $\mathrm{O}$, and fine structure excitation of atoms $\mathrm{O}$, respectively.

The quantities on the right-hand sides of Eqs. (3) and (4), denoted by $P_{a b}$, describe the type $a$ particles energy change rates as a result of elastic collisions with particles of type $b$, with large drift velocity differences having been taken into account. Thus, the quantities $P_{a b}$ contain the frictional heating produced by electric fields and thermospheric winds.

Concrete expressions of the model parameters that appear in the Eqs. (1)-(4) are the same as in the paper by Mingaleva and Mingalev (1997). By solving Eqs. (1)-(4), the time variations of the electron density, positive ion velocity, and ion and electron temperature profiles within the magnetic field tube, carried over the ionospheric heater by the convection electric field, are obtained. 
It is supposed that the plasma drift in the direction perpendicular to the magnetic field coincides with the motion of the magnetic field tube along the convection trajectory. Therefore, variations of ionospheric quantities with time are connected with their variations along the convection trajectory. It is known that the convection trajectories, around which the magnetic field tubes are carried over the polar region, are closed for a steady convection pattern. In the present study, the pattern B of the empirical convection model by Heppner (1977) is utilized, which is a steady non-substorm convection pattern. Using this convection pattern, we calculate the plasma drift velocity along the convection trajectory, which intersects the F-layer volume illuminated by the HF heating facility near Troms $\varnothing$, Scandinavia. For this convection trajectory, we obtain variations of ionospheric quantities with time (along the trajectory) by solving the system of transport equations described above.

In the model calculations, the effect of HF heating is taken into account by inclusion of the electron heat rate due to HF heating, $Q_{f}$, in the heat conduction equation for electron gas, Eq. (4). It is known that the energy absorption of a powerful HF wave in the ionosphere can take place due to various linear and nonlinear processes (see Radio Science, 9(11), 1974; Journal of Atmospheric and Terrestrial Physics, 44(12), 1982; Radio Science, 18(6), 1983; also Radio Science, 25(6), 1990). The purpose of our model calculations is not to examine various electron heating channels, but rather to investigate how the absorbed energy of an HF wave influences the large-scale high-latitude F-region modification. In the present paper we neglect some specific effects, for example, the self-structuring (self-focussing) of the wave beam and its refractive changes during the heating process. Our simplified consideration takes into account the following heating mechanism. The absorption of the heater wave energy is supposed to give rise to the formation of field-aligned plasma irregularities on a wide range of spatial scales. In particular, short-scale field-aligned irregularities are excited in the electron hybrid resonance region. These irregularities are responsible for the anomalous absorption of the electromagnetic heating wave (pump) passing through the instability region and cause anomalous heating of the plasma. The rate of this anomalous heating is denoted by $Q_{f}$ and included in the heat conduction equation for electron gas, Eq. (4). The concrete expression to the $Q_{f}$ was taken from the study by Blaunshtein et al. (1992). This expression, in spite of its simplicity, allows us to evaluate approximately the influence of the incident wave frequency on the expected large-scale high-latitude F-region modification.

The applied numerical model takes into account the variations of ionospheric quantities produced not only by powerful HF waves, but also by a natural spatial inhomogeneity of the ionosphere, which can take place in high-latitude Fregion. More complete details of the model used have been presented by Mingaleva and Mingalev (1997).

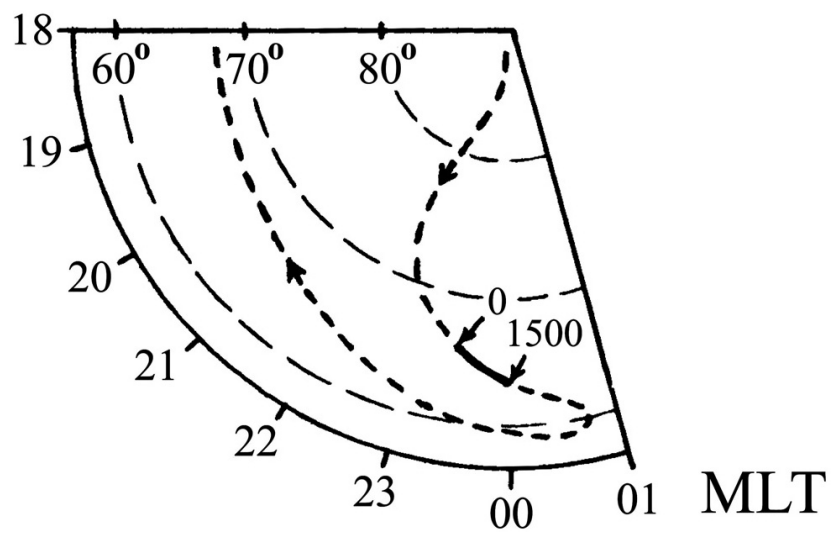

Fig. 1. The part of the convection trajectory around which the magnetic field tube of plasma is carried in the numerical simulation under nocturnal conditions (dashed line). Arrows on the trajectory indicate the direction of the convection flow. The solid line marks the displacement of the plasma tube corresponding to the period of $1500 \mathrm{~s}$ after turn-on of the HF heater.

\section{Results and discussion}

In the present study, we apply the numerical model described above for simulations of the high-latitude F-layer modification by HF waves radiated by the ionospheric heater near Troms $\emptyset$, Scandinavia, when it is located near both the midnight and noon magnetic meridians. Since the obtained results are different, it is convenient to consider the nocturnal and daytime conditions separately.

\subsection{Effects of heating in the nocturnal ionosphere}

It is generally understood now that the plasma convection can influence essentially the high-latitude F-region response to high power radio waves. In particular, the duration of a powerful HF wave effect on a heated volume of plasma cannot be unlimited in the high-latitude F-region ionosphere. The attainable duration depends on the heater parameters and plasma drift velocity. For example, the ionospheric heater near Troms $\varnothing$, Scandinavia, provides a beamwidth of about $14.50^{\circ}$. Therefore, the half-power heated region diameter is approximately $75 \mathrm{~km}$ at $300 \mathrm{~km}$ altitude (Rietveld et al., 1993). From the empirical non-substorm convection model by Heppner (1977), utilized in the present study, we can calculate the plasma drift velocity that appears to be about $400 \mathrm{~m} / \mathrm{s}$ at F2-layer altitudes for nocturnal hours and auroral latitudes. Hence, the time of about $190 \mathrm{~s}$ is the maximal period required for a plasma volume to intersect the region illuminated by the ionospheric heater at $\mathrm{F}$ 2-layer altitudes. We suppose that the HF heater is turned on and operates during a time longer than $190 \mathrm{~s}$. During this time, the considered plasma volume enters the illuminated region, intersects it, abandons it, and moves farther along the convection trajectory. The moment of the entrance in the illuminated region is the initial moment of our examination. We consider the temporal history of the ionospheric plasma in the magnetic field 


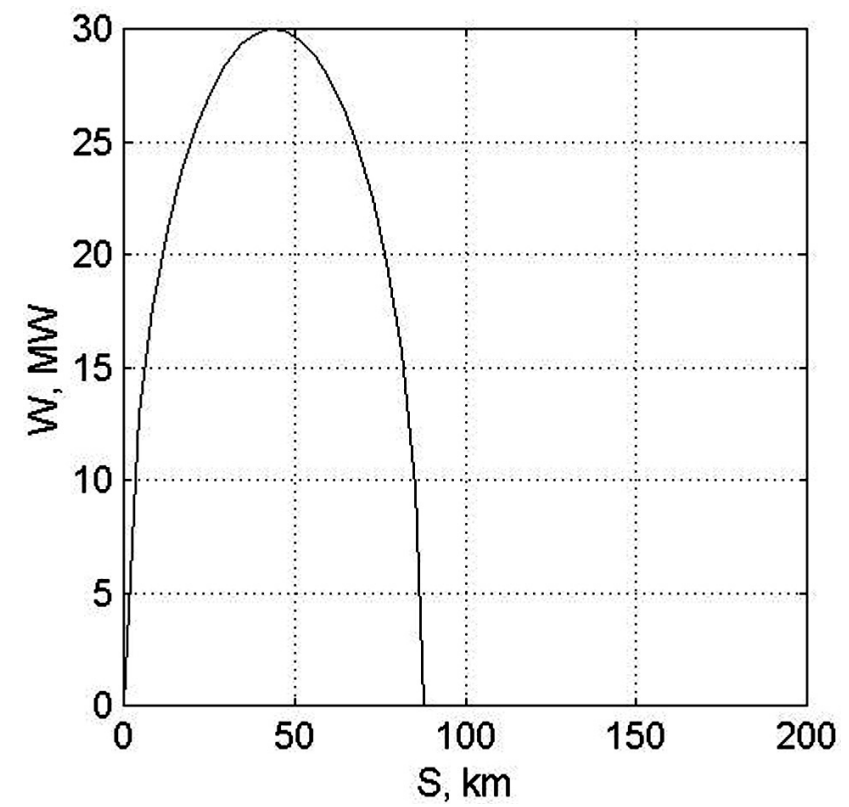

Fig. 2. The variation of the effective absorbed power (EAP) (in megawatts) along the considered part of the convection trajectory. On the horizontal axis, the distance from the beginning of the illuminated region $S$ (in $\mathrm{km}$ ) at level $h=300 \mathrm{~km}$ is shown. The center of the illuminated region lies at the distance of approximately $44 \mathrm{~km}$ where the EAP achieves the maximal value.

tube during the period of $1500 \mathrm{~s}$. This period is sufficient for the magnetic field tube to be displaced for a distance of more than $600 \mathrm{~km}$ from the HF heater. In the initial moment the considered magnetic field tube is assumed to be on the magnetic meridian of 23:20 MLT. The part of the convection trajectory, around which the plasma tube is carried in the numerical simulation under nocturnal conditions, is shown in Fig. 1.

The utilized mathematical model can describe different combinations of the solar cycle, geomagnetic activity level, and season. In the present subsection, the calculations are performed for autumn (5 November) and high solar activity $\left(F_{10.7}=230\right)$ conditions under low geomagnetic activity $\left(K_{p}=0\right)$. The considered convection trajectory is assumed to lie across a center of the illuminated region. As was noted earlier, a natural spatial inhomogeneity of the high-latitude ionosphere may take place, which leads to horizontal variations of ionospheric quantities even without any HF heating. Therefore, we started from obtaining the variations of calculated ionospheric quantities along the considered convection trajectory under natural conditions without a powerful HF wave effect. The results of simulation indicate that appreciable variations of calculated profiles may take place in the nocturnal polar ionosphere under natural conditions without HF heating, with the electron concentration at the level of the F-region peak decreasing along the considered part of the convection trajectory (corresponding to the period of $1500 \mathrm{~s}$ ). As a consequence, the F-layer critical frequency decreases along the considered part of the convection trajectory approximately from 3.35 to $3.30 \mathrm{MHz}$.

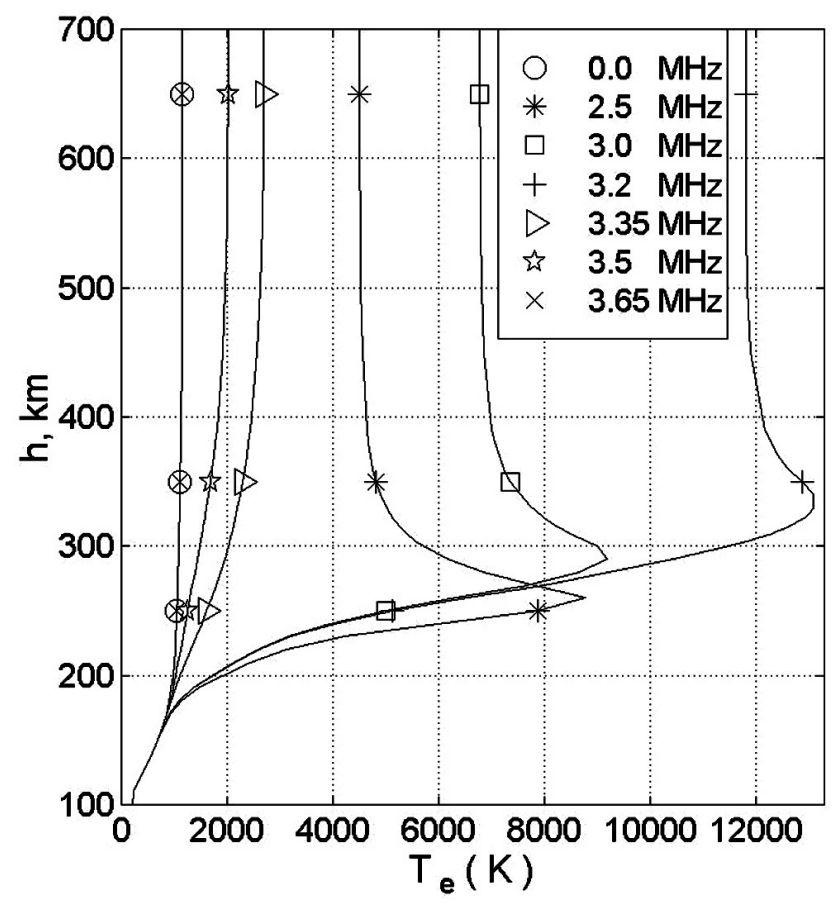

Fig. 3. Profiles of the electron temperature versus distance from the Earth along the geomagnetic field line situated in the illuminated region at $S=55.89 \mathrm{~km}$. The results are given for different HF wave frequencies: $2.5,3.0,3.2,3.35,3.5$, and $3.65 \mathrm{MHz}$, with symbol $0 \mathrm{MHz}$ indicating the results obtained under natural conditions without heating.

To investigate how the wave frequency influences the expected ionosphere's response to HF heating, we calculate the variations of ionospheric quantities along the considered part of the convection trajectory (with time) following the entrance of the plasma volume in the illuminated region for distinct cases in which HF radio waves have different frequencies: $2.0,2.5,2.8,3.0,3.2,3.35,3.5$, and $3.65 \mathrm{MHz}$. One of the important input parameters of the model is the effective absorbed power (EAP), which is the part of the effective radiated power (ERP), only. The EAP is deposited in the ambient electron gas and lost for its heating. The EAP varies on the condition that the plasma volume moves along the convection trajectory. The EAP arises, when the plasma volume enters the illuminated region, achieves a maximal value, when the plasma volume reaches a center of the illuminated region, decreases, when the plasma volume moves farther along the convection trajectory, and vanishes, when the plasma volume abandons the illuminated region. The maximal value of the EAP is assumed to be $30 \mathrm{MW}$ which is quite attainable for the heating facility near Troms $\emptyset$. Figure 2 shows the variation of the EAP along the considered part of the convection trajectory. The electron heat rate due to HF heating, $Q_{f}$, presented on the right-hand side of Eq. (4), is directly proportional to the EAP.

Let us consider the results of simulation for the convection trajectory that lies across the center of the illuminated region. 


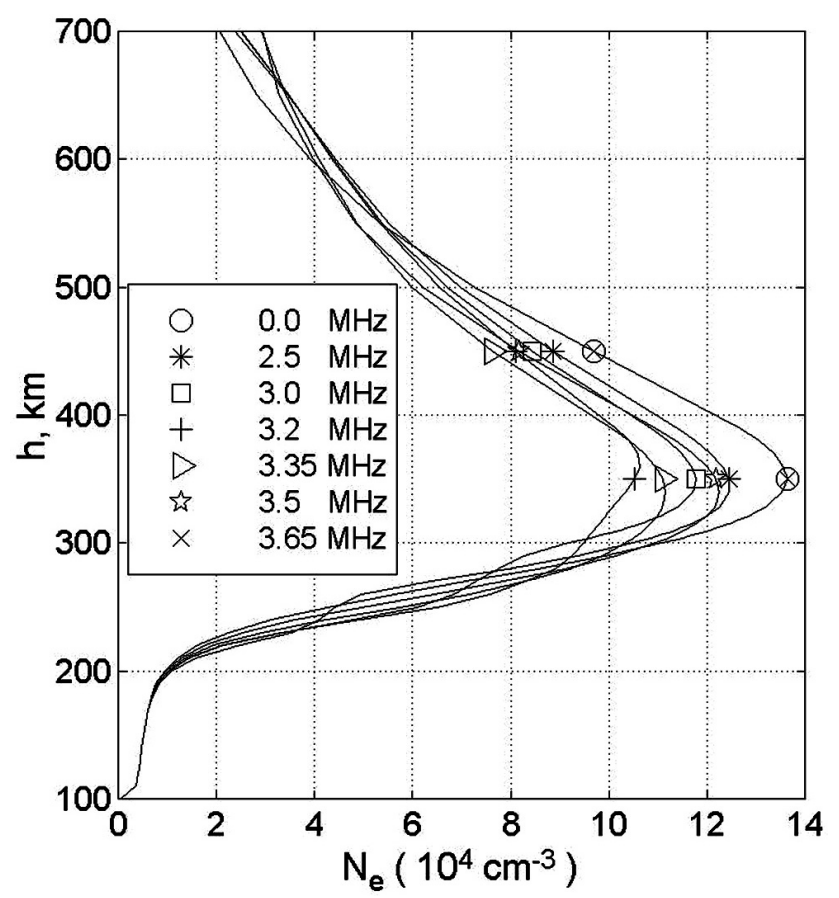

Fig. 4. Profiles of the electron concentration versus distance from the Earth along the geomagnetic field line situated in the illuminated region at $S=55.89 \mathrm{~km}$. The results are given for the same cases as in Fig. 3.

It turns out that the variations of the electron concentration, positive ion velocity, and ion and electron temperature profiles with time (along the chosen convection trajectory) following the entrance of the plasma volume in the illuminated region, obtained for such incident wave frequencies that are less than the F-layer critical frequency, are qualitatively very similar. The maximum energy input from the powerful HF wave is at the level where the wave frequency is equal to the frequency of the electron hybrid resonance. At this level, a pronounced peak arises in the electron temperature profile due to the great energy input from the powerful HF wave. At this peak, the electron temperature can increase for some thousands of degrees. Figure 3 presents calculated profiles of the electron temperature for the point of the considered part of the convection trajectory located in the illuminated region. As a consequence of the great increase in the electron temperature, the upward and downward ionospheric plasma fluxes arise from the level where the electron temperature peak is located. Indeed, the increase in the electron temperature results in a rise in the electron gas pressure. From the level where the electron gas pressure peak is located, the upward and downward electron gas fluxes arise. Due to the electrical neutrality of the ionospheric plasma, the ion gas begins to move, too. Thus, ionospheric plasma fluxes arise from the level where the maximum energy input from the powerful HF wave takes place. As a consequence, the upward component of plasma velocity can achieve values of more than $100 \mathrm{~m} / \mathrm{s}$ near the level of the F2-region peak. Vis-

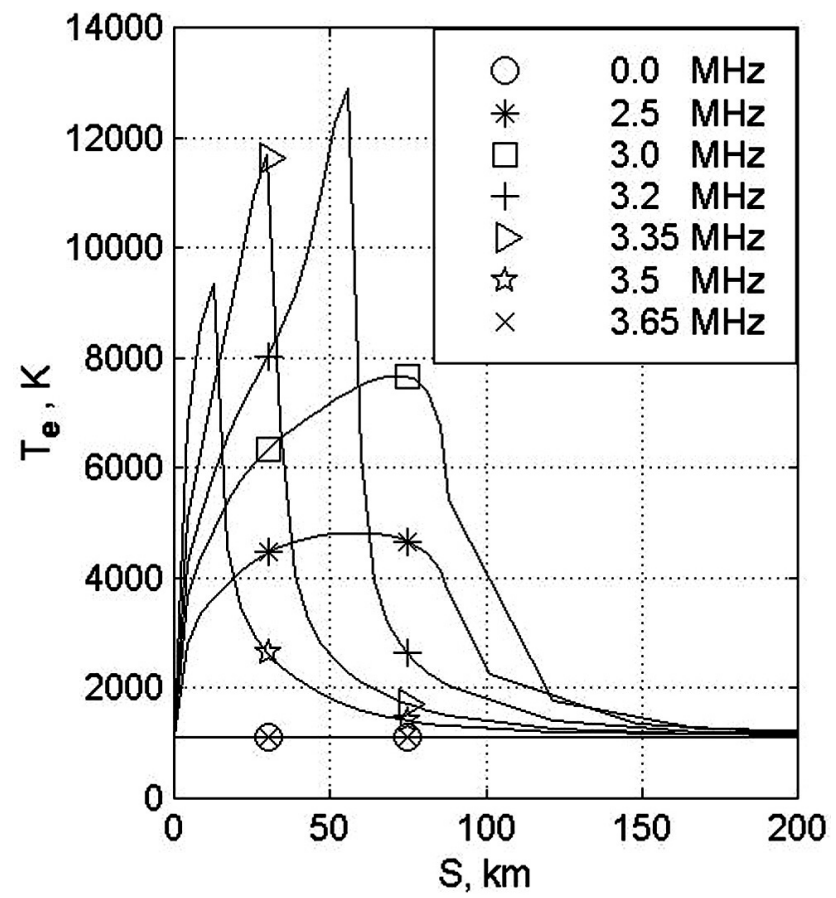

Fig. 5. The variations of the electron temperature (in absolute degrees) along the considered part of the convection trajectory at level $h=350 \mathrm{~km}$. The results are given for different HF wave frequencies: $2.5,3.0,3.2,3.35,3.5$, and $3.65 \mathrm{MHz}$. The results, obtained under natural conditions without a powerful HF wave effect, are indicated by symbol $0 \mathrm{MHz}$.

ible changes in the electron concentration profile can be produced by the ionospheric plasma fluxes, with the electron concentration decreasing in the F2-layer at higher heights than the height of maximum energy absorption from the powerful HF wave. The decrease in the electron concentration can be significant not only near the level of maximum energy absorption from the powerful HF wave, but also near the F-region peak. Figure 4 presents calculated profiles of the electron concentration for the same point of the considered part of the convection trajectory as in Fig. 3.

After the abandonment of the illuminated region by the magnetic field tube, the electron temperature decreases due to elastic and inelastic collisions between electrons and other particles of ionospheric plasma. Figure 5 presents the variations of the electron temperature along the considered part of the convection trajectory at the level close to the F-layer peak. It can be seen that the amplitudes of variations of the electron temperature produced by powerful HF waves achieve the maxima at a point close to the back edge of the illuminated region $(S \approx 88 \mathrm{~km})$, after which a region of the recovery of the electron temperature begins. The duration of the period of the electron temperature recovery after the HF heating is about 3 min at F2-layer levels.

For the cases in which incident wave frequencies are with confidence below the F-layer critical frequency, the increase in the amplitudes of variations of the electron temperature with heating frequency takes place. This increase is inter- 


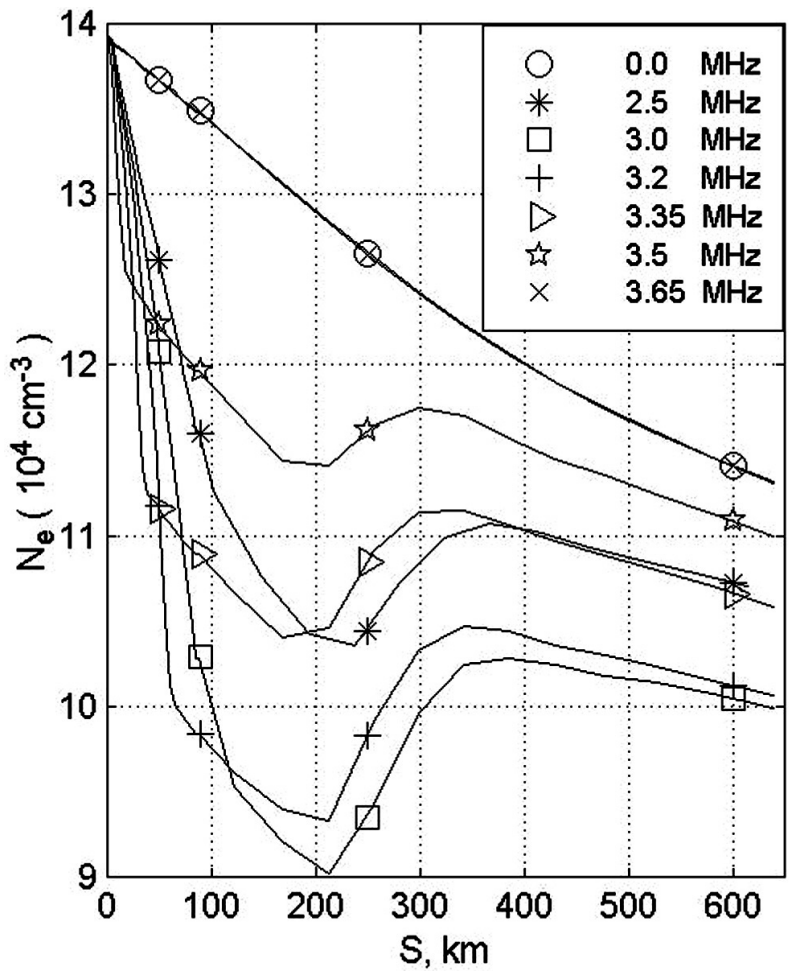

Fig. 6. The variations of the electron concentration (in units of $10^{4} \mathrm{~cm}^{-3}$ ) along the considered part of the convection trajectory at level $h=350 \mathrm{~km}$. The captions are the same as in Fig. 5 .

preted as being caused by the change in the electron hybrid resonance height, which is known to rise with heating frequency in the regular F-layer. When the electron hybrid resonance height rises, the electron cooling rates due to elastic and inelastic collisions between electrons and neutral particles decrease at this height because of an exponential drop in the neutral particles densities. If the electron cooling rates become smaller, the electron temperature ought to increase. Thus, for the cases in which incident wave frequencies are with confidence less than the F-layer critical frequency, the more incident the wave frequency is, the higher the electron temperature variation amplitude, produced by the HF heating, ought to be.

Results of simulation indicate that the electron heating is possible when the transmitter operates at frequencies that exceed the F-layer critical frequency, with the HF waves passing through the ionosphere without a reflection. However, the exceeding can only be less than $0.3 \mathrm{MHz}$. Indeed, the electron temperature variations, obtained at the frequency of $3.65 \mathrm{MHz}$ which exceeds the F-layer critical frequency for $0.3 \mathrm{MHz}$, coincide with the results, obtained under natural conditions without a powerful HF wave effect. The maximal frequency of incident waves, at which the anomalous heating of the plasma is possible, will be called "threshold of incident wave frequency" or TIWF. Using the well-known formula for the electron hybrid resonance frequency, we obtain

$\mathrm{TIWF}=\left(f_{c}^{2}+f_{H}^{2}\right)^{\frac{1}{2}}$,

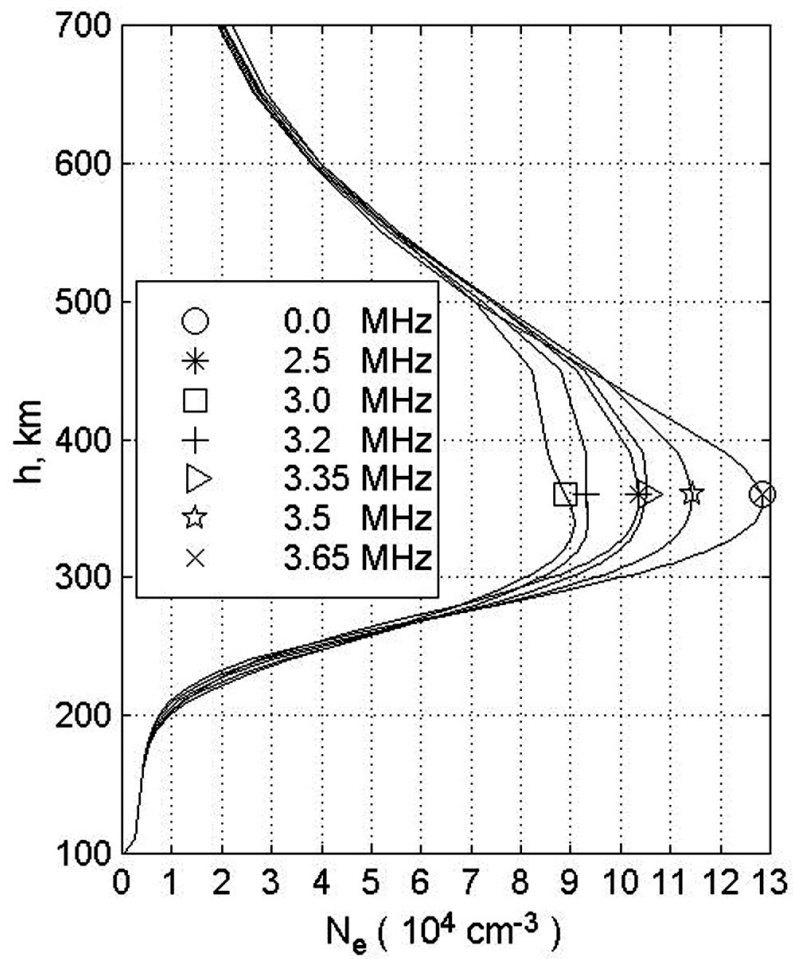

Fig. 7. Profiles of the electron concentration versus distance from the Earth along the geomagnetic field line, calculated for the point of the considered part of the convection trajectory which is located at $S=212.6 \mathrm{~km}$. The results are given for the same cases as in Fig. 3.

where $f_{c}$ is the F-layer critical frequency and $f_{H}$ is the electron cyclotron frequency. It can be seen that the TIWF depends on the F-layer critical frequency and is slightly more than that.

The variations of the electron concentration along the considered part of the convection trajectory at the level near to the F-layer peak are shown in Fig. 6. It is seen from results presented that the appreciable decrease of the electron concentration along the considered part of the convection trajectory takes place under natural conditions without HF heating. For the cases in which the HF heater operates, more appreciable decreases of the electron concentration along the considered part of the convection trajectory are produced by the energy input from the powerful HF waves. It is seen that the electron concentration decreases not only in the illuminated region, but also after the abandonment of it by the magnetic field tube. For the cases in which incident wave frequencies are with confidence less than the F-layer critical frequency, the electron concentrations at the level of the F-region peak achieve the minima at a distance from the ground-based HF heater of about $160 \mathrm{~km}$. In addition, the more the incident wave frequency is, the smaller the electron concentration turns out to be. A powerful HF wave should lead to a decrease of more than $27 \%$ in electron concentration at the level of the F-region peak when the incident wave frequency is $3 \mathrm{MHz}$. Figure 7 presents profiles of the elec- 

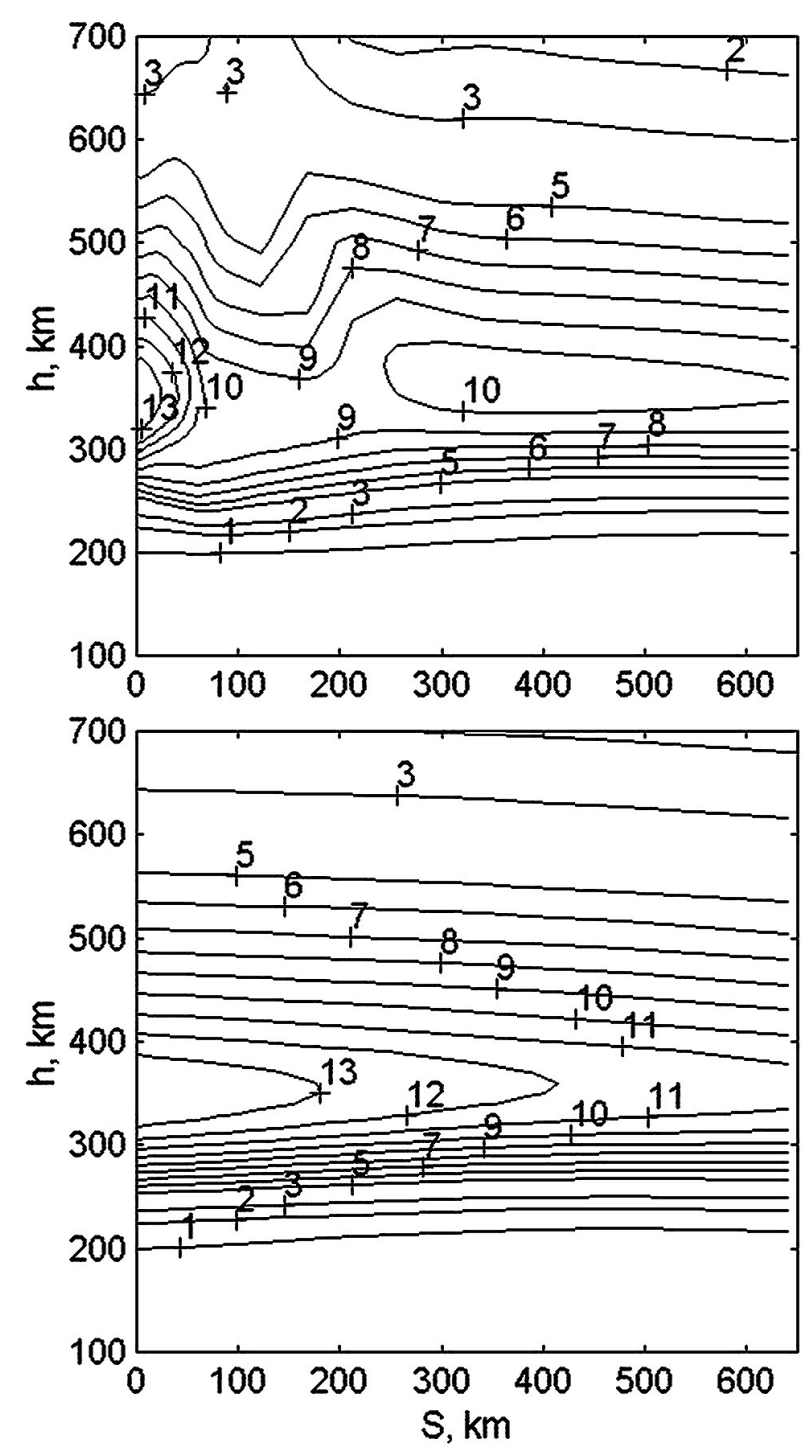

Fig. 8. The calculated isolines of the electron concentration (in units of $10^{4} \mathrm{~cm}^{-3}$ ) over the considered part of the convection trajectory obtained at night under natural conditions without HF heating (bottom panel) and on condition that the powerful HF wave has the frequency of $3.2 \mathrm{MHz}$ (top panel).

tron concentration calculated for the point of the convection trajectory near to the point in which the minimal values of the electron concentration at the level of the F-region peak are achieved.

As a consequence of a decrease in the electron concentration conditioned by the powerful HF wave, the F-layer critical frequency decreases along the considered part of the convection trajectory. Therefore, the effect of the powerful HF wave on the plasma volume can be broken off due not only to its abandoning the illuminated region, but also to the decrease in the TIWF below the incident wave frequency, even though the plasma volume continues to remain in the illuminated region. It is seen from the results presented that to obtain the maximal effect of HF heating on the electron concentration at the level near to the F-layer peak, the iono-

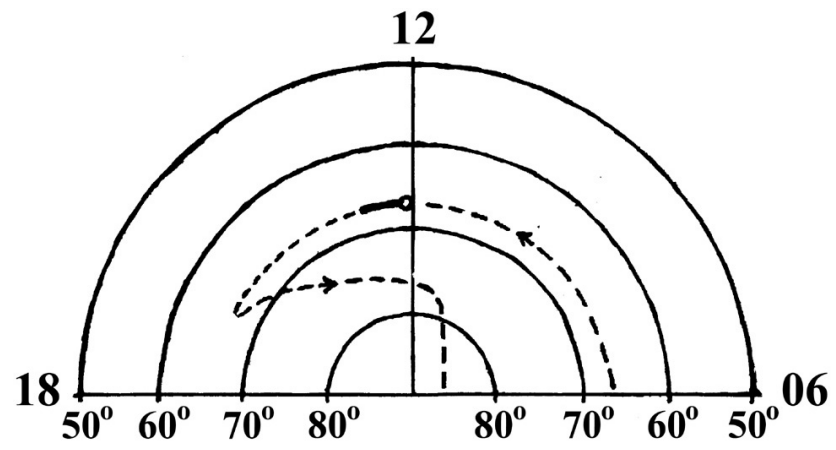

Fig. 9. The part of the convection trajectory around which the magnetic field tube of plasma is carried in the numerical simulation under daytime conditions (dashed line). Arrows on the trajectory indicate the direction of the convection flow. The solid line marks the displacement of the plasma tube corresponding to the period of 80 min after turn-on of the HF heater.

spheric heater has to operate at a frequency slightly less than the F-layer critical frequency. This frequency will be called the most effective frequency and denoted by $f_{\text {eff. }}$ The difference between the $f_{c}$ and $f_{\text {eff }}$ ought to be about $0.35 \mathrm{MHz}$ in the nocturnal high-latitude F-region, on condition that the F-layer critical frequency is $3.35 \mathrm{MHz}$. Figure 8 presents the computed isolines of the electron concentration over the considered part of the convection trajectory, obtained under natural conditions, without a powerful HF wave effect and on condition that a high-power, high-frequency radio wave does have an effect, respectively. It is seen that the appreciable large-scale modification of the nocturnal high-latitude F-region can be produced by powerful HF waves when the ionospheric heater operates at a frequency close to the most effective frequency.

The results of numerical simulations indicate that significant variations in the electron temperature and concentration distributions can be produced by HF heating in the nocturnal high-latitude F-layer. The amplitude of the increase in the electron temperature at F-layer altitudes ought to achieve its maximum inside the illuminated region (Fig. 5). On the contrary, the amplitude of the decrease in the electron concentration at F2-layer altitudes ought to achieve its maximum at the distance of about $160 \mathrm{~km}$ from the ground-based HF heater, under nocturnal conditions (Figs. 6 and 8). Evidently, the minimal values of the electron concentration in the nocturnal high-latitude ionosphere are not found straight over a ground-based HF heater but are displaced from it by rather a large distance. This displacement is due to the convection of the ionospheric plasma and is the main specific feature of the high-latitude ionosphere that can obstruct ordinary observations of the F-layer modification by HF heating at night.

\subsection{Effects of heating in the daytime ionosphere}

The model simulations analogous to those described in the previous subsection were performed for daytime conditions. In the daytime, at latitudes of Troms $\varnothing$, Scandinavia, the available drift velocity of the ionospheric plasma at F2-layer 


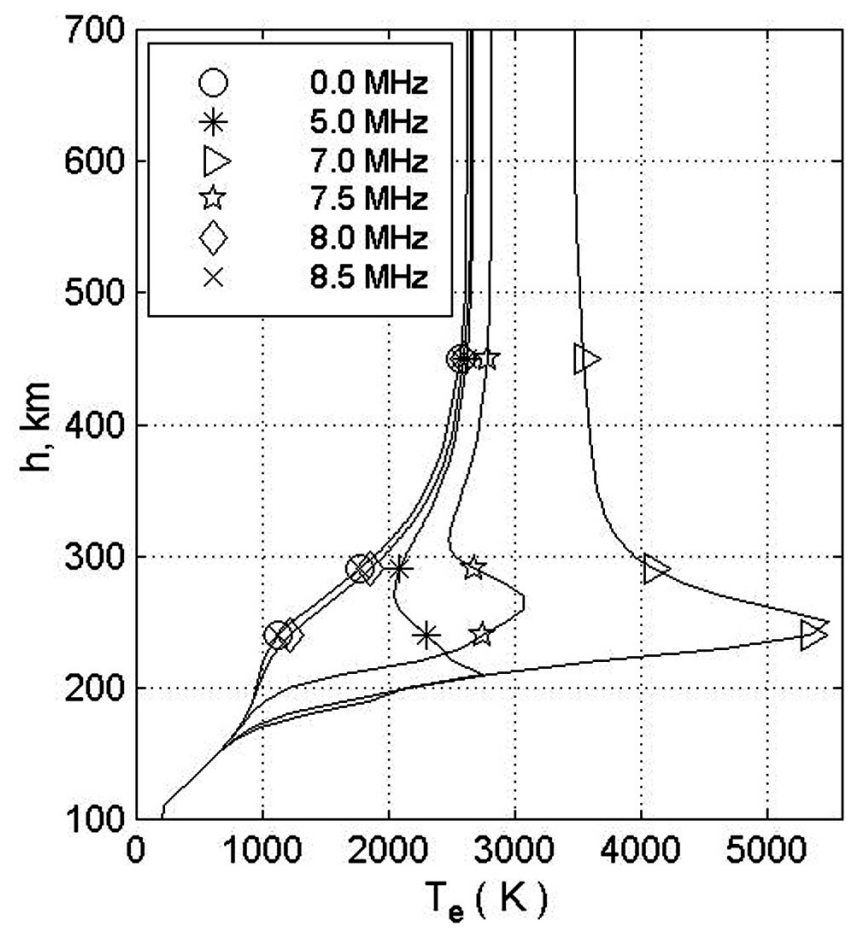

Fig. 10. Profiles of the electron temperature versus distance from the Earth along the geomagnetic field line situated in the illuminated region at $S=62.71 \mathrm{~km}$. The results are given for different HF wave frequencies: $5.0,7.0,7.5,8.0$, and $8.5 \mathrm{MHz}$, with symbol $0 \mathrm{MHz}$ indicating the results obtained under natural conditions without $\mathrm{HF}$ heating.

altitudes is much less than that under nocturnal conditions. Therefore, the period required for a plasma volume to intersect the region illuminated by the ionospheric heater at F2-layer altitudes in the daytime ionosphere is much more than that in the nocturnal ionosphere. Moreover, plasma of the daytime ionosphere at latitudes of Troms $\varnothing$, Scandinavia has a tendency to corotate with the Earth in addition to the magnetospheric-driven flow. Therefore, the convection trajectory, which lies near the considered ionospheric heater, when it is located near the noon magnetic meridian, has the configuration shown in Fig. 9. It is presumed that the part of the magnetic field tube is carried in the numerical simulation around the convection trajectory shown in Fig. 9. The moment of the entrance of the considered part of the magnetic field tube in the illuminated region is the initial moment of our examination. We suppose that the HF heater is turned on and operates during a time longer than the period required for the part of the magnetic field tube to intersect the illuminated region at F2-layer altitudes. This period is to be approximately $10 \mathrm{~min}$ under noon conditions. During this period, the considered part of the magnetic field tube enters the illuminated region, intersects it, abandons it, and moves farther along the convection trajectory. We consider the temporal history of the ionospheric plasma in the part of the magnetic field tube during the period of about $80 \mathrm{~min}$. Since time may be connected with the distance along the trajectory using the plasma drift velocity, we can establish that the consideration

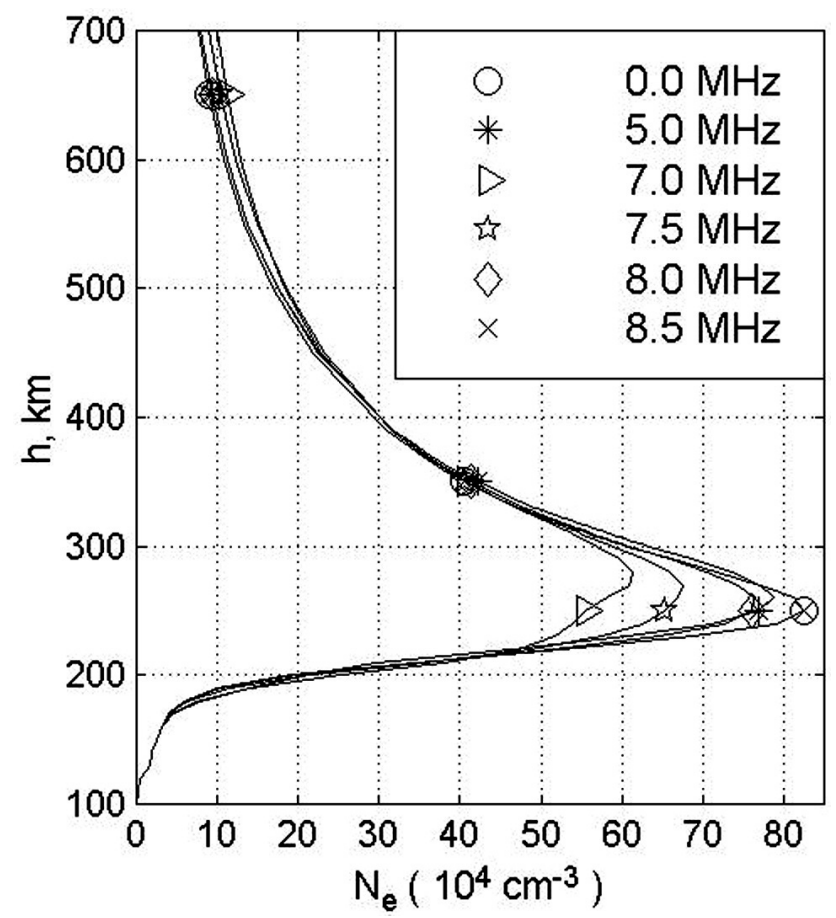

Fig. 11. Profiles of the electron concentration versus distance from the Earth along the geomagnetic field line situated in the illuminated region at $S=85.39 \mathrm{~km}$. The results are given for the same cases as in Fig. 10.

period $(\approx 80 \mathrm{~min})$ is sufficient for the magnetic field tube to be displaced for a distance of more than $600 \mathrm{~km}$ from the HF heater. This displacement is shown in Fig. 9 by the solid line. At the initial moment, the considered part of the magnetic field tube is assumed to be near the magnetic meridian of 12:00 MLT. The considered convection trajectory is assumed to lie across the center of the illuminated region. The calculations of the present subsection are performed for autumn (5 November) and middle solar activity $\left(F_{10.7}=130\right)$ conditions under low geomagnetic activity $\left(K_{p}=0\right)$.

It is known that the high-latitude ionosphere possesses a natural spatial inhomogeneity that leads to horizontal variations of ionospheric parameters, even without any HF heating. Therefore, we started from obtaining the variations of calculated ionospheric parameters along the considered part of the convection trajectory under natural conditions without a powerful HF wave effect. The obtained variations turned out to be much less than those obtained in the previous subsection under nocturnal conditions. However, the electron concentration at the F-region levels turned out to be much more than the one obtained under nocturnal conditions. As a consequence, the F-layer critical frequency obtained in the daytime turned out to be much more than that obtained at night.

Next, we obtained the variations of ionospheric parameters along the considered part of the convection trajectory (with time) following the entrance of the magnetic field tube in the illuminated region for distinct cases in which HF radio 


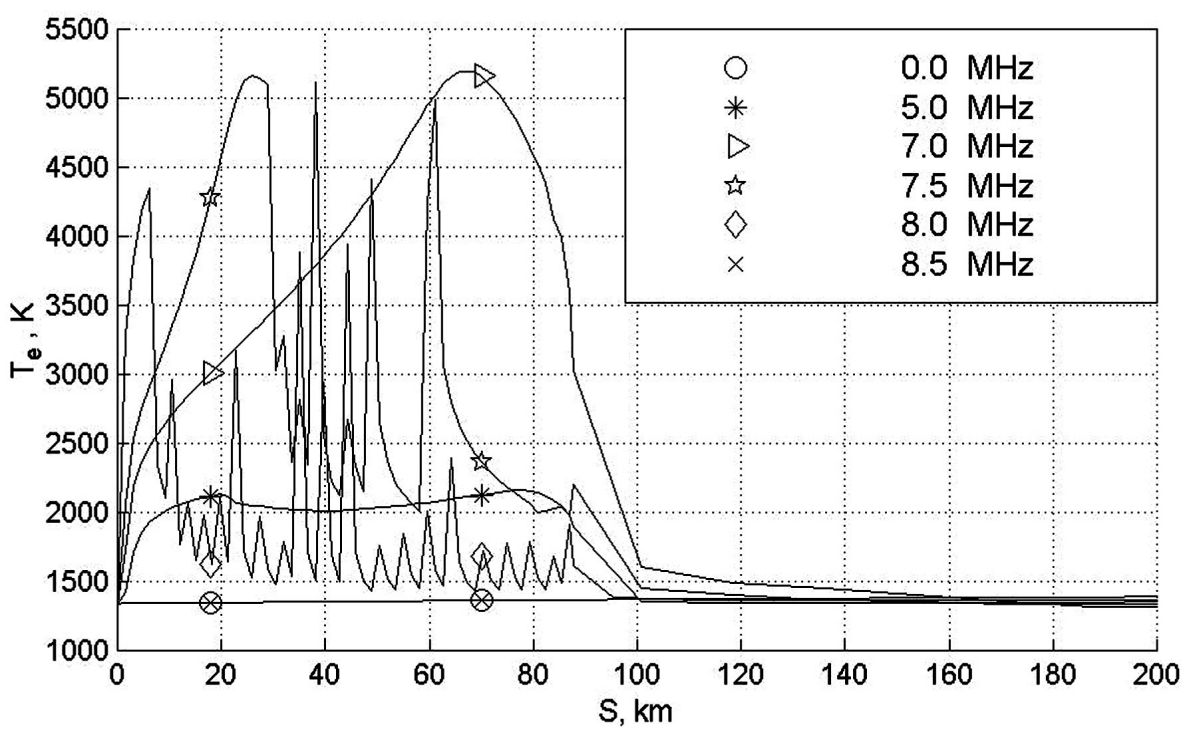

Fig. 12. The variations of the electron temperature (in absolute degrees) along the considered part of the convection trajectory at the level of $260 \mathrm{~km}$. The results are given for different HF wave frequencies: 5.0, 7.0, 7.5, 8.0, and 8.5 MHz. The results, obtained under natural conditions without a powerful HF wave effect, are indicated by symbol $0 \mathrm{MHz}$. The distance from the beginning of the illuminated region $S$ (in $\mathrm{km}$ ) at level $h=300 \mathrm{~km}$ is shown on the horizontal axis. The center of the illuminated region, where the EAP achieves the maximal value, is located at $S \approx 44 \mathrm{~km}$.

waves have different frequencies: 4.0, 5.0, 5.5, 6.0, 6.5, 7.0, $7.5,8.0$, and $8.5 \mathrm{MHz}$. It should be noted that the F-layer critical frequency has a value of $8.2 \mathrm{MHz}$ at the initial moment of our examination. The important input parameter of the numerical model is the effective absorbed power (EAP). In the present subsection, the EAP is assigned in such a way as in the previous subsection (Fig. 2). The maximal value of the EAP is assumed to be $30 \mathrm{MW}$, i.e. the same as in the nocturnal conditions.

It turned out that essential variations of the electron temperature, positive ion velocity, and electron concentration profiles with time (along the chosen convection trajectory) can be produced by powerful HF waves in the high-latitude F-region in the daytime. These variations obtained for such HF wave frequencies that are with confidence less than the F-layer critical frequency, are qualitatively very similar. A pronounced peak arises in the electron temperature profile at the level where the wave frequency is equal to the frequency of the electron hybrid resonance. Figure 10 presents electron temperature profiles calculated for the point of the considered part of the convection trajectory that is located in the illuminated region. As a consequence of the great increase in the electron temperature, the upward and downward ionospheric plasma fluxes arise from the level where the electron temperature peak is located. Visible changes in the electron concentration profile are ultimately produced by the energy input from the powerful HF wave. These changes arise not only near the level of maximum energy absorption from the powerful HF wave, but also above this level, including the height of the F-region peak, with the electron concentration decreasing in the F-layer. Figure 11 presents calculated profiles of the electron concentration for the point of the con- sidered part of the convection trajectory that is located in the illuminated region. The mechanisms responsible for the variations of ionospheric parameters in the daytime are identical to the mechanisms operated at night.

The variations of the electron temperature and concentration along the considered part of the convection trajectory at the level near to the F-layer peak are shown in Figs. 12 and 13, respectively. It can be seen that, for the cases in which HF wave frequencies are with confidence less than the F-layer critical frequency, the variation behaviors are analogous to those obtained under nocturnal conditions. However, conspicuous distinctions between the locations of the points, where the electron concentration achieves a minimum at the level of the F-layer peak, calculated for day and night conditions, take place. In the daytime, such a point is located at a distance from the ground-based HF heater of about $50 \mathrm{~km}$, whereas this distance was about $160 \mathrm{~km}$ at night. This is the consequence of the distinction between the plasma drift velocities obtained for day and night conditions. The profiles of the electron concentration, obtained for the point of the convection trajectory near to the point in which the minimal values of the electron concentration at the level of the F-region peak are achieved, are shown in Fig. 11. It is seen that the differences between heated and unheated electron concentrations at the level near to the F-region peak depend significantly on the value of the frequency of HF wave.

It can be noticed that the anomalous heating of the plasma is possible when the transmitter operates at frequencies that slightly exceed the F-layer critical frequency. The maximal frequency of HF waves, at which anomalous heating of the plasma is possible, called the "threshold of incident wave frequency" or the TIWF, is given by Eq. (5). It is seen from the 


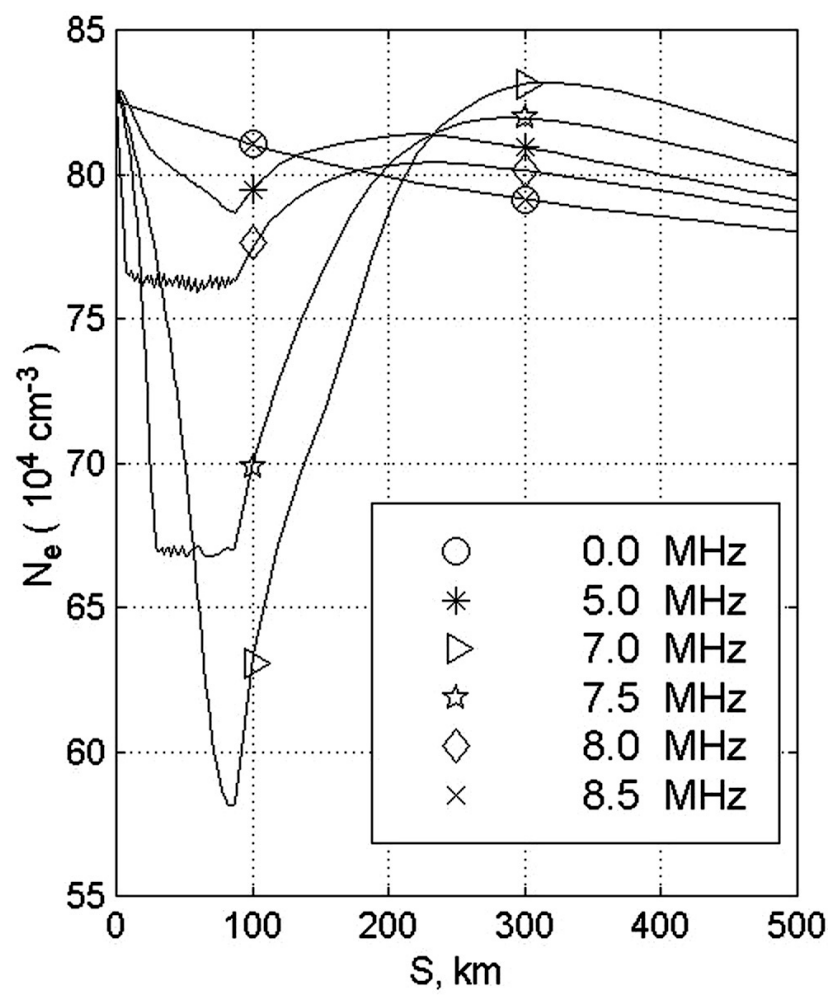

Fig. 13. The variations of the electron concentration (in units of $10^{4} \mathrm{~cm}^{-3}$ ) along the considered part of the convection trajectory at the level of $260 \mathrm{~km}$. The captions are the same as in Fig. 12.

results presented (Figs. 11 and 13) that HF heating leads to a decrease in the electron concentration at the level of the F-region peak. As a consequence, the F-layer critical frequency ought to decrease. Consequently, the TIWF is to decrease, too. Therefore, the effect of HF heating on the ionospheric plasma in the part of the magnetic field tube can be broken off due not only to the abandonment of the illuminated region by it, but also to the decrease in the TIWF below the HF wave frequency, even though the plasma tube continues to be in the illuminated region. Exactly such events take place during the period of the HF heater operation in the cases when HF wave frequencies are close to the Flayer critical frequency (Figs. 12 and 13). Such events have taken place under nocturnal conditions in the previous subsection. However, the results of the present subsection differ on principle from the results obtained for nocturnal conditions. At night, the electron concentration continues to decrease smoothly after the moment of the TIWF decrease below the HF wave frequency. In the daytime, on the contrary, the electron concentration begins to increase after the moment of the TIWF decrease below the HF wave frequency, when the effect of HF heating is broken off. The increase in the electron concentration, which is due to photoionization, leads to an increase in the F-layer critical frequency, as well the TIWF. As a consequence, in some period of time, the TIWF reaches the HF wave frequency, and the effect of HF heating is turned on again. HF heating leads to a decrease in the electron concentration at the level of the F-region peak
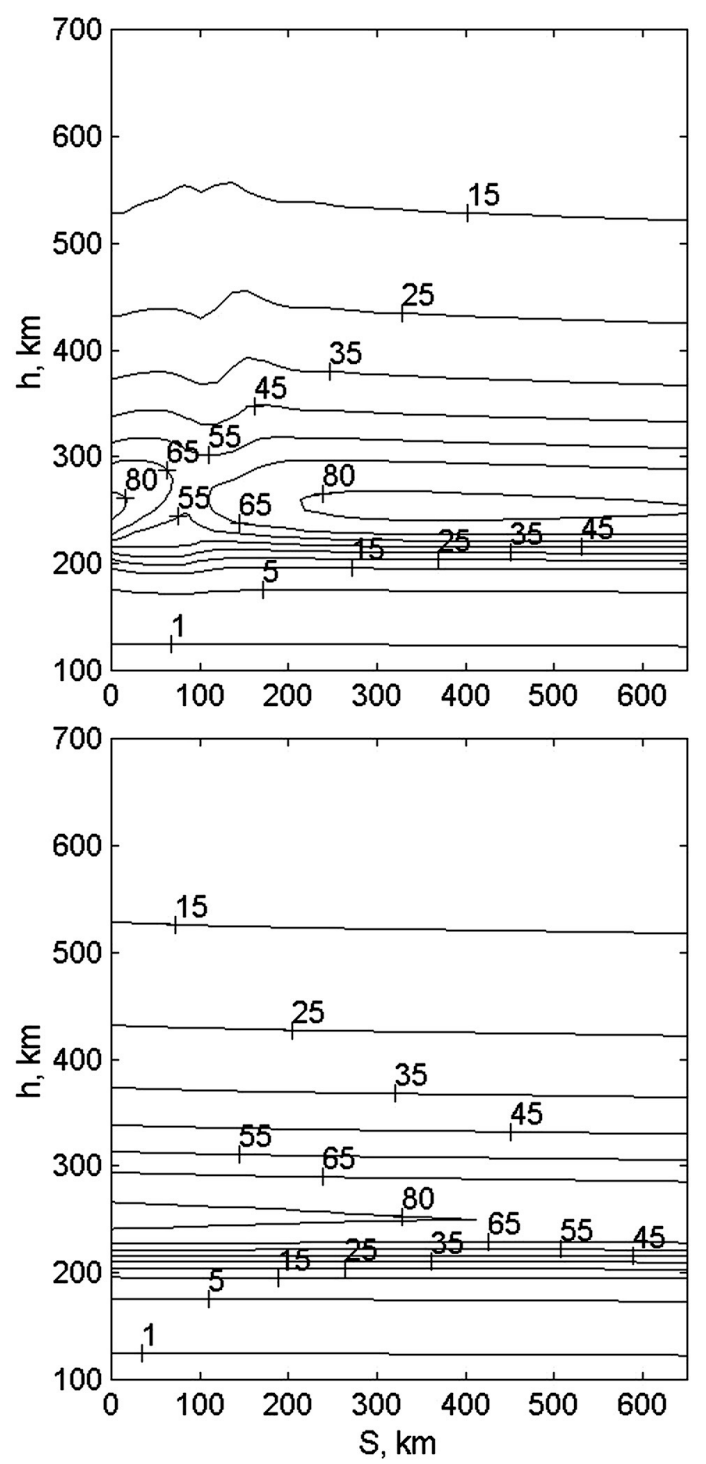

Fig. 14. The calculated isolines of the electron concentration (in units of $10^{4} \mathrm{~cm}^{-3}$ ) over the considered part of the convection trajectory obtained in the daytime under natural conditions without HF heating (bottom panel) and on condition that the powerful HF wave has the frequency of $7.0 \mathrm{MHz}$ (top panel).

and the process will begin to repeat itself. The very irregular, sawtooth-like curves, presented in Figs. 12 and 13 and obtained at $\mathrm{HF}$ wave frequencies of 7.5 and $8.0 \mathrm{MHz}$, are interpreted as being caused by the mechanism described above. Thus, this mechanism can be responsible for the formation of the electron concentration irregularities having a horizontal extent of a few kilometers in the high-latitude F-region illuminated by powerful HF waves.

The results of numerical simulations indicate that to obtain the maximal effect of HF heating on the electron concentration at the level near the F-layer peak in the daytime ionosphere, the HF heater has to operate at the most effective frequency, $f_{\text {eff }}$, which is slightly less than the F-layer critical frequency, $f_{c}$. In the daytime, the difference between $f_{c}$ and $f_{\text {eff }}$ ought to be about $1.2 \mathrm{MHz}$ on condition that the 
F-layer critical frequency is $8.2 \mathrm{MHz}$. Powerful HF waves should lead to a decrease of up to $30 \%$ in electron concentration at the level of the F-region peak in the daytime, with the results depending significantly on the value of the frequency of the HF wave.

The computed isolines of the electron concentration over the considered part of the convection trajectory are presented in Fig. 14. From this figure, it can be seen that the appreciable large-scale modification of the daytime high-latitude F-region may be produced by powerful HF waves. The minimal values of the electron concentration are not found straight over a ground-based HF heater but are displaced from it for some distance. The daytime value of this distance ought to be about $50 \mathrm{~km}$.

\section{Summary and concluding remarks}

The numerical model of the high-latitude ionosphere, which can be affected by powerful HF waves, has been applied for simulations of the high-latitude F-layer modification by HF waves, both for nocturnal and for daytime conditions. This paper has not examined various electron heating channels conditioned by different linear and nonlinear processes initiated by powerful HF waves in the ionospheric plasma. Our focus here has been on the influence of the absorbed energy of heating HF waves on the large-scale F-region modification. Therefore, we have taken into account the only heating mechanism and neglected some specific effects of the heating process. Account has been taken only of the anomalous heating of the plasma in the presence of small-scale fieldaligned irregularities in the vicinity of the electron hybrid resonance frequency. We have taken advantage of the expression to the rate of anomalous heating, derived by Blaunshtein et al. (1992) and utilized earlier by other authors, for a numerical simulation of the mid-latitude ionosphere behavior (Vas'kov et al., 1993). This expression, in spite of its simplicity, permits one to evaluate approximately the influence of the heating HF wave frequency on the large-scale highlatitude F-region modification. Our simulations were performed for the point with geographic coordinates of the ionospheric heater near Troms $\varnothing$, Scandinavia for autumn conditions.

The results of numerical simulations indicated that the plasma convection leads to principal distinctions between high- and mid-latitude ionospheres, as for the F-layer modification by a powerful HF wave. The convection of plasma restricts the duration of a powerful HF wave effect on a heated volume of plasma. As a consequence of this restriction, the efficiency of the HF heating may be decreased in the highlatitude F-region as compared with the mid-latitude F-region. Moreover, the plasma convection obstructs ordinary observations of the high-latitude F-layer modification by HF heating. Indeed, the amplitude of the decrease of the electron concentration at the F2-layer altitudes, produced by powerful $\mathrm{HF}$ waves, does not achieve its maximum straight over a ground-based HF heater. The minimal values of the electron concentration can be displaced for rather a long distance from the HF heater, with the displacement being due to the convection of the ionospheric plasma. The distance between the ground-based HF heater and the point, where the electron concentration achieves a minimum at the level of the F-layer peak, can achieve the value of about $160 \mathrm{~km}$ under nocturnal conditions and about $50 \mathrm{~km}$ under daytime conditions.

Nevertheless, the simulation results indicated that conspicuous variations of the electron temperature, positive ion velocity, and electron concentration profiles can be produced by HF heating in the high-latitude F-region, both under nocturnal and under daytime conditions, with the maximal amplitudes of the variations depending appreciably on the value of the frequency of the HF waves. The changes in the largescale structure of the high-latitude F-region are small, when the frequency of HF waves is much lower than the F-layer critical frequency $f_{c}$, increase, when the incident wave frequency rises, achieve a maximum, when the heating frequency approaches the most effective frequency $f_{\text {eff }}$, decrease, when the pump frequency continues to rise, and vanish, when the injected frequency surpasses the TIWF (threshold of incident wave frequency) defined in Eq. (5). It appears that the most effective frequency, $f_{\text {eff }}$, has distinct values for nocturnal and daytime conditions. For nocturnal conditions,

$f_{\text {eff }} \approx(0.88 \div 0.93) f_{c}$,

in the daytime,

$f_{\text {eff }} \approx(0.83 \div 0.88) f_{c}$.

It can be seen that the most effective frequency ought to be slightly less than the F-layer critical frequency, $f_{c}$. Thus, the closer the incident wave frequency is to the most effective frequency, the higher the values ought to be of the maximal amplitudes of variations of ionospheric quantities, produced by the HF heating.

The simulation results indicated that powerful HF waves can lead to a decrease of about $30 \%$ in electron concentration at the level of the F-region peak. This decrease is a consequence of the great increase in the electron temperature. The numerically obtained electron temperature can increase for some thousands of degrees at the level of the F-region peak. As was noted earlier, we apply a simplified model description of the heating process. Moreover, for a concrete heating experiment, some input parameters of the model are not exactly known, in particular, the EAP (effective absorbed power), which is a part of the effective radiated power (ERP) only. Therefore, it is possible that, for a concrete heating experiment, numerically obtained values of the electron temperature and concentration will differ from the real values of these ionospheric parameters. However, it is hoped that the strong dependence of heater induced electron temperature and concentration changes at the level of the F-region peak on the incident wave frequency, obtained by the numerical simulation, corresponds to reality. Generally, the validity of this dependence may be substantiated experimentally only.

Nevertheless, the obtained frequency dependence of the large-scale high-latitude F-region modification caused by 
high power radio waves can be applied for an explanation of ionospheric heating experiments carried out earlier. It is known that in many actual experiments enhancements of the electron temperature and depletions in the electron density were not observed at the level of the F-region peak. It may be expected that in these experiments the incident wave frequencies used turned out to be far from the most effective frequency, $f_{\text {eff }}$, or exceeded the TIWF (threshold of incident wave frequency). On the contrary, in the experiments where the large-scale changes in the electron temperature and concentration at the F-region altitudes were observed (Jones et al., 1986; Honary et al., 1995; Robinson et al., 1996; Tereshchenko et al., 2000; Gustavsson et al., 2001), it is probable that the heating frequencies turned out to be close to the most effective frequency, $f_{\text {eff }}$. The heating frequency closest to the most effective frequency, $f_{\text {eff }}$, took place probably in the ionospheric heating experiment carried out by Gustavsson et al. (2001) when the electron temperature was raised to $3500 \mathrm{~K}$ at the F-region altitudes.

Thus, for the preparation and organization of artificial modification experiments by HF radio waves in the highlatitude F-region, it is recommended that the diagnostic facilities are placed skillfully, with the direction of the plasma convection having to be taken into account. Moreover, the incident wave frequency is recommended to be chosen very carefully.

Acknowledgements. The authors would like to thank the referees for qualitative comments and helpful advices that led to great improvement in the original manuscript.

Topical Editor M. Lester thanks M. Rietveld and another referee for their help in evaluating this paper.

\section{References}

Blaunshtein, N. Sh., Vas'kov, V. V., and Dimant, Ya. S.: Resonance heating of the F-region by a powerful radio wave, Geomagn. and Aeron., 32(2), 95-99, 1992,(Russian issue).

Djuth, F. T., Thide, B., Ierkic, H. M., and Sulzer, M.P.: Large F-region electron-temperature enhancements generated by highpower HF radio waves, Geophys. Res. Lett., 14, 953-956, 1987.

Duncan, L. M., Sheerin, J. P., and Behnke, R. A.: Observations of ionospheric cavities generated by high-power radio waves, Phys. Rev. Lett., 61, 239-242, 1988.

Frolov, V. L.,Eruchimov, L. M., Metelev, S. A., and Sergeev, E. N.: Temporal behavior of artificial small-scale irregularities: Review of experimental results, J. Atmos. Terr. Phys., 59, 2317-2324, 1997.

Gordon, W. E. and Carlson, H. C.: Arecibo heating experiments, Radio Sci., 9, 1041-1047, 1974.

Gustavsson, B., Sergienko, T., Rietveld, M. T., Honary, F., Steen, A., Brandstrom, B. U. E., Leyser, T. B., Aruliah, A. L., Aso, T., Ejiri, M., and Marple, S.: First tomographic estimate of volume distribution of HF-pump enhanced airglow emission, J. Geophys. Res., 106, 29 105-29 124, 2001.

Hansen, J. D., Morales, G. J., Duncan, L. M., and Dimonte, G.: Large-scale HF-induced ionospheric modification: experiments, J. Geophys. Res., 97, 113-122, 1992.
Heppner, J. P.: Empirical models of high-latitude electric fields, J. Geophys. Res., 82, 1115-1125, 1977.

Honary, F., Stocker, A. J., Robinson, T. R., Jones, T. B., and Stubbe, P.: Ionospheric plasma Response to HF radio waves operating at frequencies close to the third harmonic of the electron gyrofrequency, J. Geophys. Res., 100, 21 489-21 501, 1995.

Jones, T. B., Robinson, T. R., Stubbe, P., and Kopka, H.: EISCAT observations of the heated ionosphere, J. Atmos. Terr. Phys., 48, 1027-1035, 1986.

Kapustin, I. N., Pertsovskii, R. A., Vasil'ev, A. N., Smirnov, V. S., Raspopov, O. M., Solov'eva, L. E., Ul'yanchenko, A. A., Arykov, A. A., and Galachova, N. V.: Generation of radiation at combination frequencies in the region of the auroral electric jet, JETP Lett., 25, 228-231, 1977.

Mantas, G. P., Carlson, H. C., and La Hoz, C. H.: Thermal response of F-region ionosphere in artificial modification experiments by HF radio waves, J. Geophys. Res., 86, 561-574, 1981.

Mantas, G. P.: Large 6300- $\AA$ airglow intensity enhancements observed in ionosphere heating experiments are exited by thermal electrons, J. Geophys. Res., 99, 8993-9002, 1994.

Mingalev, V. S. and Mingaleva, G. I.: Numerical simulation of the high-latitude F-layer modification by HF waves with different powers, in: "Physics of Auroral Phenomena" Proc. XXII Annual Seminar, Apatity, pp. 61-64, 1999.

Mingaleva, G. I. and Mingalev, V. S.: Response of the convecting high-latitude F-layer to a powerful HF wave, Ann. Geophysicae, 15, 1291-1300, 1997.

Rietveld, M. T., Kohl, H., Kopka, H., and Stubbe, P.: Intcoduction to ionospheric heating at Troms $\varnothing-1$. Experimental overview, J. Atmos. Terr. Phys., 55, 577-599, 1993.

Robinson, T. R., Honary, F., Stocker, A. J., Jones, T. B., and Stubbe, P.: First EISCAT observations of the modification of F-region electron temperatures during RF heating at harmonics of the electron gyro frequency, J. Atmos. Terr. Phys., 58, 385-395, 1996.

Rodriguez, P., Kennedy, E. J., Keskinen, M. J., Siefring, C. L., Basu, Sa., McCarrick, M., Preston, J., Engebretson, M., Kaiser, M. L., Desch, M. D., Goetz, K., Bougeret, J.-L., and Manning, R.: The WIND-HAARP experiment: Initial results of high power radiowave interactions with space plasmas, Geophys. Res. Lett., 25, 257-260, 1998.

Stubbe, P.: Review of ionospheric modification experiments at Troms $\varnothing$, J. Atmos. Terr. Phys., 58, 349-368,1996.

Stubbe, P. and Kopka, H.: Summary of results obtained with the Troms $\varnothing$ heating facility, Radio Sci., 18, 831-834, 1983.

Tereshchenko, E. D., Koslova, M. O., Evstafiev, O. V., Khuducon, B. Z., Nygren, T., Rietveld, M., and Brekke, A.: Irregular structures of the F-layer at high latitudes during ionospheric heating, Ann. Geophysicae, 18, 1197-1209, 2000.

Utlaut, W. F. and Violette, E. J.: A summary of vertical incidence radio observations of ionospheric modification, Radio Sci, 9, 895903, 1974.

Vas'kov, V. V., Dimant, Ya. S., and Ryabova, N. A.: Magnetospheric plasma thermal perturbations induced by resonant heating of the ionospheric F-region by high-power radio wave, Adv. Space Res., 13, (10)25-(10)33, 1993.

Warner, L. S., Goldstein, J. A., Lind, R. W., Wong, A. Y., and McCarrick, M. J.: Channel probe observations of the auroral ionosphere during high-power auroral stimulation heating experiments, Radio Sci., 25, 1251-1267, 1990. 